\title{
Research and Development of Food Industry's Three-Dimensional Printing
}

\author{
Ramil Nezhmetdinov ${ }^{1, *}$, Ilya Kovalev ${ }^{1}$, Pavel Melikov ${ }^{1}$, and Sergey Sokolov ${ }^{1}$ \\ ${ }^{1}$ MSUT STANKIN, 127055 Vadkovskiy per. 3a, Moscow, Russia
}

\begin{abstract}
In the presented article, the problem of building a specialized plant for food 3D printing is considered, which allows printing with various food semi-finished products with minimal changeover or without it. The developed plant, including all its software and hardware components, should be flexible and, according to the principles of construction and use, should approach the analogs of additive equipment existing on the market and to the classical control systems corresponding to it, but have more functionality and a lower price. The development of such compact solutions will make it possible to use them both for small cafes, restaurants, and in large factories.
\end{abstract}

\section{Introduction}

The level of automation of production processes is steadily growing each year, and it also increases in food industries such as confectionery factories, small restaurants and others. Almost you can't find any modern food production without the use of automated equipment, since its use makes it possible to manufacture food products that are subject to requirements for the accuracy of the recipe base and the reproducibility of technological conditions (temperature, processing time, and others).

In the modern world, the food production of confectionery products of complex geometric shapes and different colors is often completely manually. This type of production does not allow you to get products with high graphic or geometric complexity, and is also characterized by low productivity.

The proposed work is aimed at increasing the level of automation of the confectionery production process and systematizing the methods of designing confectionery products through the use of tools and software packages used in other industries (for example, in mechanical engineering) [1].

The main goal of this work is to expand the range of assortment of single food products by using additive technology and a digital control system (serial types).

\footnotetext{
*Corresponding author: neramil@gmail.com
} 


\section{Analysis of similar solutions}

To form a list of characteristics of the presented solution, which will provide a competitive market advantage and determine the list of requirements for the construction of such a solution, a comparative analysis of the parameters and functionality of the existing desktopsize food 3D printing installations on the world market and the developed solution was carried out, which is presented in Table 1.

Table 1. Comparison of existing solutions with the developed one

\begin{tabular}{|c|c|c|c|c|}
\hline Characteristics & $\begin{array}{l}\text { DISCOV3RY 2.0 } \\
\text { COMPLETE [3] }\end{array}$ & $\begin{array}{c}\text { Choc Creator } \\
\text { V2.0 Plus } \\
{[4]}\end{array}$ & $\begin{array}{c}\text { PancakeBot } \\
{[5]}\end{array}$ & Developed solution \\
\hline Print speed & $55 \mathrm{gr} /$ hour & $60 \mathrm{gr} /$ hour & $600 \mathrm{ml} / \mathrm{h}$ & $\begin{array}{c}150 \mathrm{gr} / \text { hour for chocolate } \\
\text { and more than } 600 \mathrm{ml} / \mathrm{h} \\
\text { for dough }\end{array}$ \\
\hline $\begin{array}{c}\text { Volume of stored } \\
\text { material }\end{array}$ & $2 \times 60 \mathrm{ml}(120 \mathrm{ml})$ & $30 \mathrm{ml}$ & $400 \mathrm{ml}$ & $150-500 \mathrm{ml}$ \\
\hline Print material & Gels & Pastas (chocolate) & Pastes (dough) & $\begin{array}{c}\text { Pastas (chocolate, dough } \\
\text { and ice cream) }\end{array}$ \\
\hline Functional systems & $\begin{array}{l}\text { No (feed system } \\
\text { only) }\end{array}$ & $\begin{array}{l}\text { Material melting } \\
\text { system }\end{array}$ & $\begin{array}{c}\text { Material baking } \\
\text { system }\end{array}$ & $\begin{array}{l}\text { Melting, cooling, and } \\
\text { baking systems }\end{array}$ \\
\hline CNC System & Marlin & Marlin & Marlin & Marlin \\
\hline Print type & FDM & FDM & FDM & FDM \\
\hline
\end{tabular}

When considering the existing solutions for food 3D printing on the market, it's possible to distinguish one pattern: the core of automation in most of them is a microcontroller platform with a Marlin control system, the machine parameters of which were configured for printing food products of the same type (pancakes, chocolate figurines, etc.). This fact significantly limits the flexibility of these systems in terms of the range of printed products, as well as the ability to connect individual installations into a single ecosystem (virtual workshop or laboratory) for the implementation of centralized management $[2,3]$.

In addition to Marlin, there are similar control systems in the class: Repetier-Firmware and RepRap Firmware, but they are closed and have less flexibility (the number of supported platforms is small, or consists only of proprietary solutions) and for these reasons they are not adapted for food 3D printing [4].

It is worth noting that many existing solutions do not have a material baking system (for example, a heated table), and the vast majority do not have a cooling system (for example, a compressor system based on dry ice or Peltier modules), both of which are necessary for building a flexible printing plant [5].

Based on the analysis, the requirements for the developed system were formulated:

- using a full-fledged Linux operating system as a numerical control system terminal, allows to combine individual plants together and provide a complex user interface;

- a hardware platform with significantly more power and flexibility for creating management programs, launching them, and providing additional services;

- The plant must include tooling to implement a wide range of printing capabilities focused on the food industry. 


\section{General structural model of the plant and its components}

The proposed solution is based on the FDM printer (fused deposition modeling, FDMModeling via layer-by-layer deposition) for printing with plastic, which is equipped with modules developed in the course of work:

- Chocolate feeding system (extruder), consisting of a heated hopper (master heating circuit), a tube system with a heater, a control unit for the slave heating circuit and a print head;

- Cooling system based on Peltier modules which controlled by a CNC system;

- IoT technology integration module based on a single-board computer $[6,7]$.

The block diagram of both the hardware and the software parts (Figure 1) of the threedimensional printing plant is based on the principle of using common software and hardware modules, among which the following main software components can be distinguished: functional extensions for the CNC system [8, 9], written in the $\mathrm{C}$ programming language, providing advanced control of the installation, which interacts with the WEB terminal implemented on a single-board computer via the UART interface [10, 11].

In Figures 1 the elements included in the research area are highlighted in color.

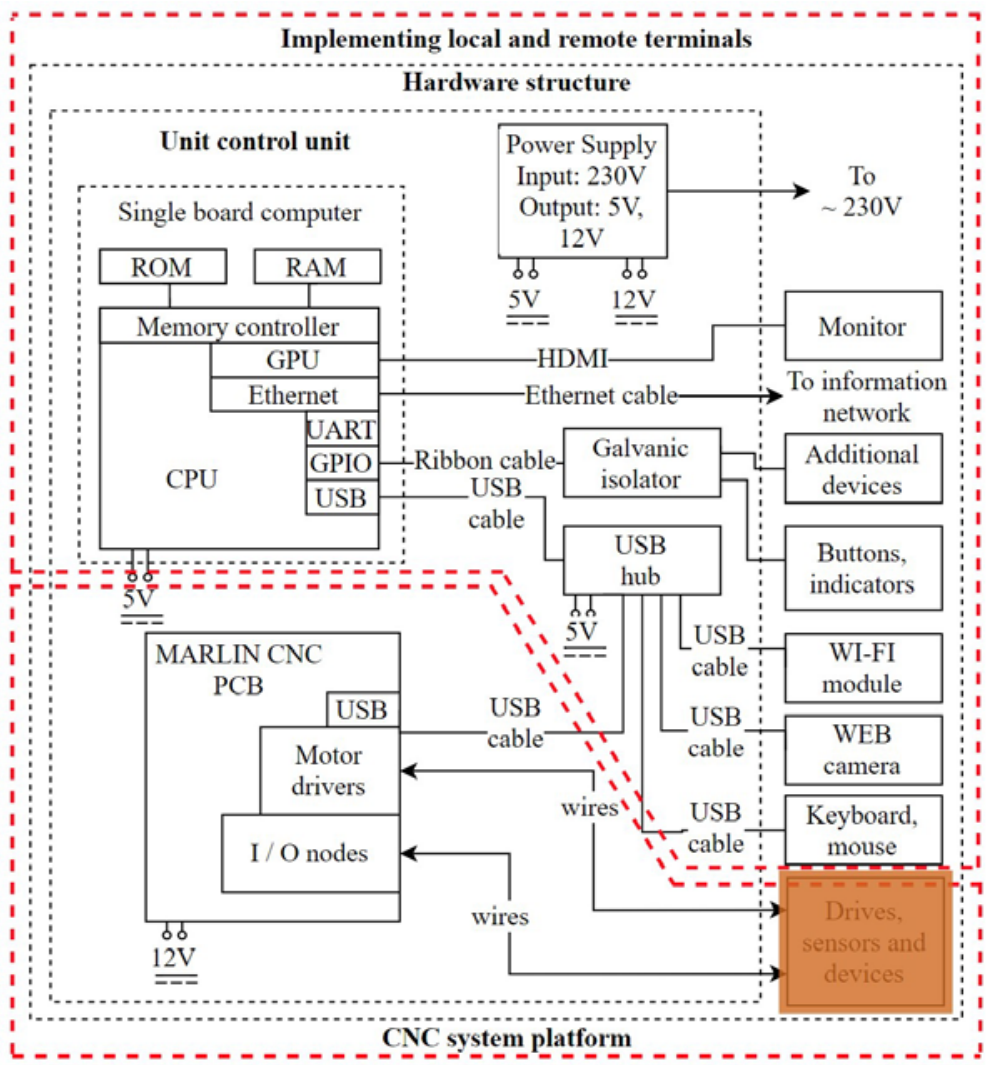

Fig. 1. Hardware model of the solution

To realize the coverage of the largest number of print materials, it is necessary to implement systems for feeding and heating the material, as well as its cooling.

There is a need to build a heating system, consisting of at least two circuits, which is to achieve a fast rate of melting of the material in the hopper, since a large volume of material 
has a high heat capacity. The bunker is installed outside the thermal box, due to different heat losses in the tube (located in the cold temperature zone) and in the bunker (located in the room temperature zone) and in view of the great complexity of balancing these heat losses - the need to divide the heating system into two circuits is confirmed. The block diagram of the proposed heating system is shown in Figure 2.

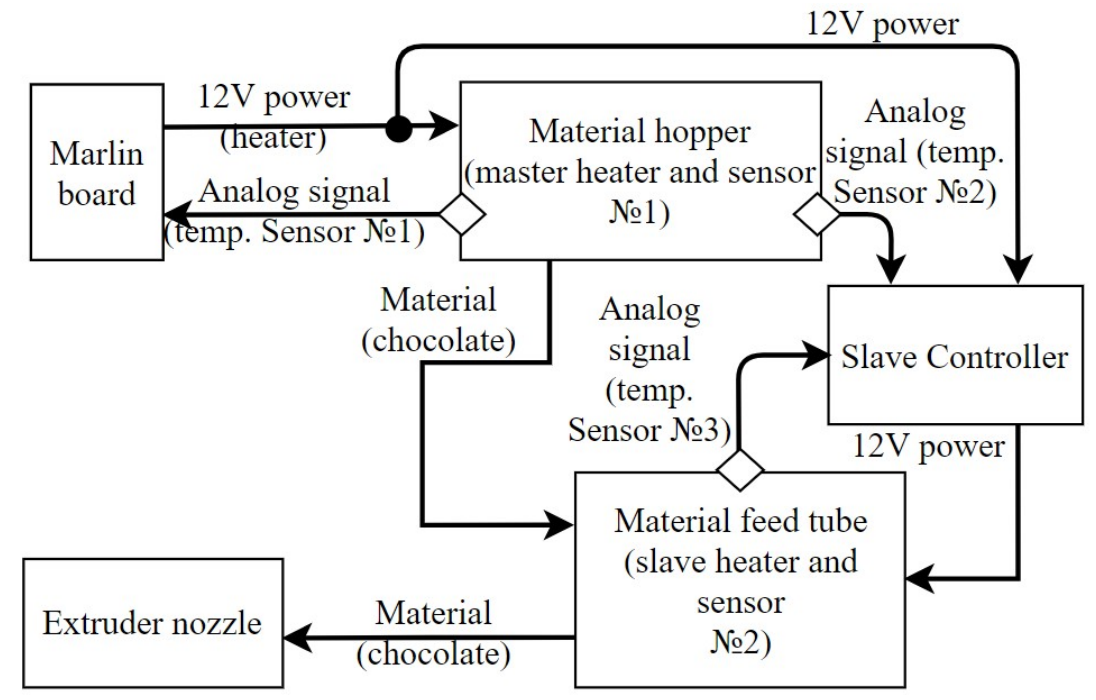

Fig. 2. Double-circuit heating structure

The essence of the presented scheme is as follows:

1)Marlin controls the temperature of the feed hopper by sensor №1, in which the material is stored, and sets some stable temperature on it;

2)The controller of the driven heating circuit has two temperature sensors: Sensor №2 is installed in the hopper, and Sensor №3 is installed in the heating supply tube. The controller tries to maintain the temperature on the tube equal to the temperature in the hopper. This ensures the operability of the driven heating circuit.

Next, the material is baked with a heated table (in the case of dough) or hardens under the influence of blowing or cooling system (in the case of chocolate or ice cream).

As structural elements of the cooling system, it is assumed to use the developed installation based on Peltier modules, which is due to the condition of compactness of the developed solution [12].

Since the standard Marlin board has only one control circuit for the extruder heater, and two control circuits are selected for the implementation of the heating system, it is necessary to develop a controller for the driven heating circuit [13].

\section{Practical implementation of a prototype 3D printing installation}

The Figure 3 shows the developed WEB-interface of the terminal of the control and monitoring system. The main elements on it are: "Visualization", allowing you to monitor the progress of printing, the "Settings" group of elements, where you can change the print parameters, and the screen for selecting control programs [14].

The terminal implements all three modes, classic for CNC systems: AUTO, JOG (jogging, input mode for one movement block), MDI (Manual Data Input mode). This is 
done as a first step towards unifying the functionality of the control system and its terminal. Also, screens adapted for food production have been partially implemented, where, for example, it's possible to select a printing profile for specific materials, which is more analogous to the combination of the "Machine parameters" and "Tool" screens of traditional $\mathrm{CNC}$ systems [15]. The industry alternative to the Machine Settings screen refers to the selection of a configuration of connected tooling or modules for food printing, and the Tool screen refers to the selection of different profiles for printing with specific materials.

The qualification of an advanced user will make it possible for him to change the configurations of the food installation and print profiles on the fly from the WEB-interface. Also, the architecture of the solution allows to broadcast a photo stream from a printer in a remote operator terminal due to the ability to connect a camera, which is useful for longterm printing or when combining several installations into one control terminal (the ability to select and configure connections is implemented).

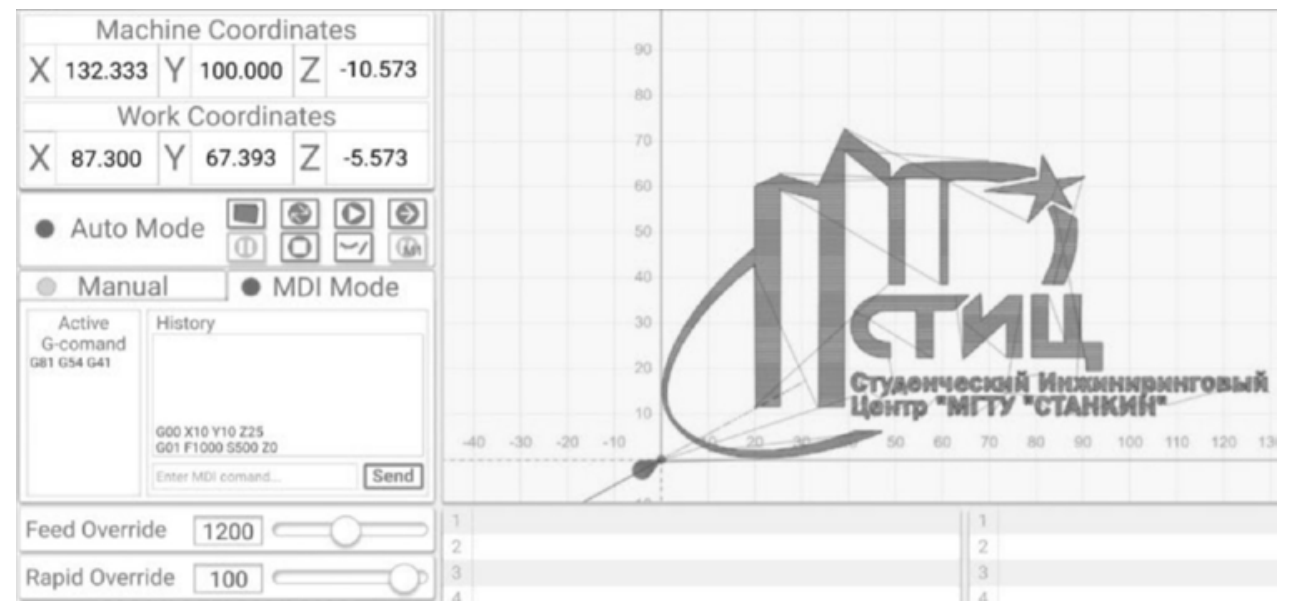

Fig. 3. Developed Web terminal

The electrical circuit diagram of the developed controller of the driven heating circuit is shown in Figure 4 and it is a primitive temperature comparator. The core of the circuit is the industrial operational amplifier $\operatorname{lm} 158$ or its consumer analog $\operatorname{lm} 358$, which is connected according to the comparator circuit, in which the resistor R3 provides the switching hysteresis of the slave heating circuit [16].

To implement the material cooling system required for printing with chocolate or printing with curing liquids (ice cream printing), it is necessary to ensure a uniform cold throughout the entire volume of the print. For this purpose, there was realized a thermal box (picture 8) from the thermal insulating material Penoplex with thickness of $5 \mathrm{~cm}$ and thermal conductivity $0,03 \mathrm{~W} / \mathrm{m}^{\circ} \mathrm{K}$.

On the back side of the thermal box two spigots for circulation of the cooled air between the thermal box and the cooling system are installed. On the front side there is a removable door made of the same material as the thermal box itself.

In accordance with the generalized structural diagrams the more detailed diagram and 3D models of the nodes (in the CAD module of SolidWorks) of the cooling, feeding and heating system have been developed, which is shown in Fig. 4.

These $3 \mathrm{D}$ models were physically produced (mostly by 3D printing from plastic) [17]. 

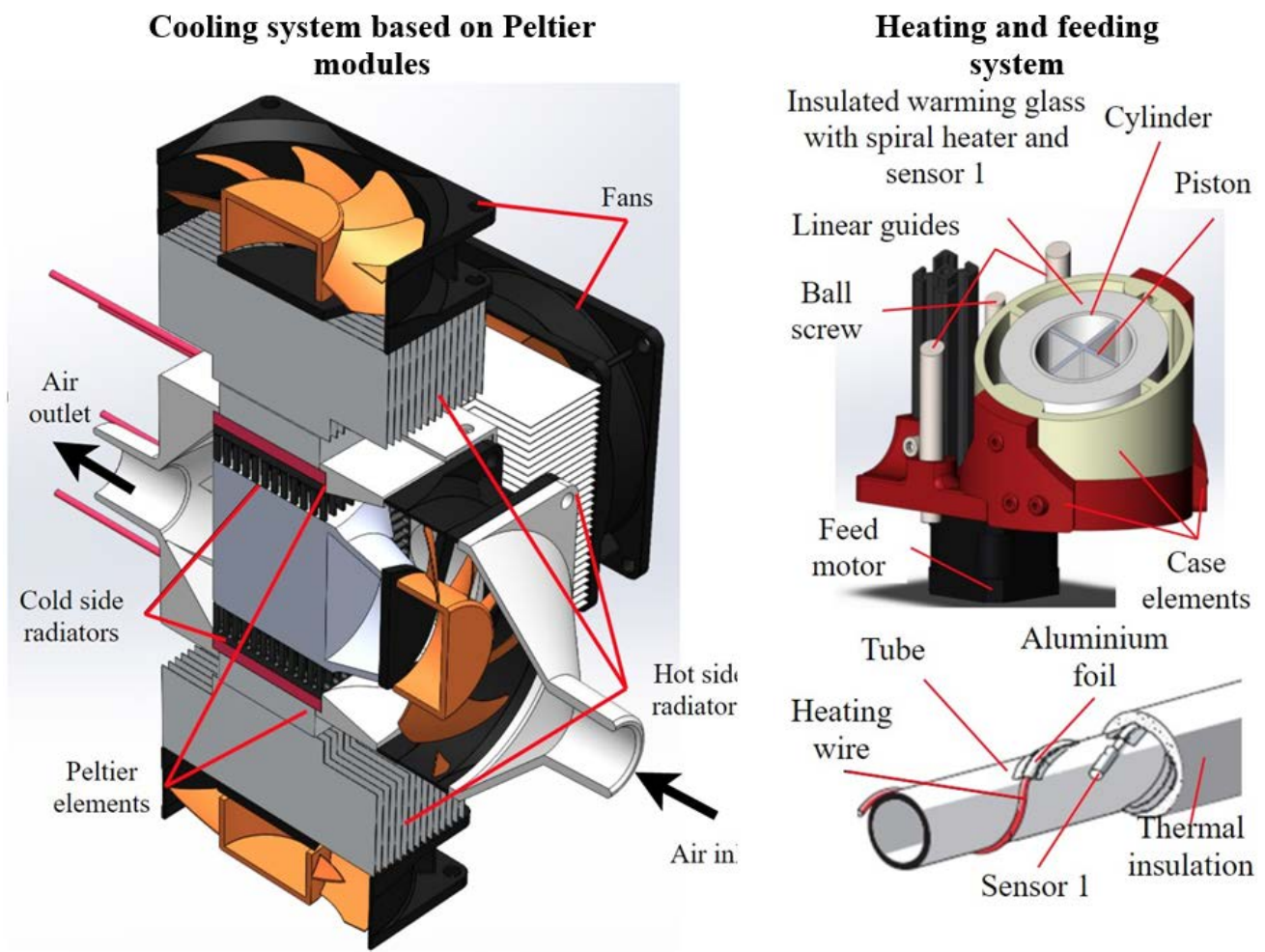

Fig. 4. Prototype tooling

\section{Prototype tests and evaluation of the results}

The tests carried out on the prototype of the plant (Figure 5) showed that all the hardware and software elements of the plant, except the cooling system, function in a given mode and without failures during prolonged operation in various modes of printing chocolate and at different environmental parameters.

The result of the module-based cooling system is negative. When $150 \mathrm{~W}$ of energy is consumed, the air flow is cooled by $3^{\circ} \mathrm{C}$. This is not enough for $3 \mathrm{D}$ printing with chocolate, so it is necessary to use an industrial compressor-type refrigerator, which will make the installation less compact.

The feed system based on the Nema 17HS4401 motor, a linear drive based on a screw drive with a pitch of $2 \mathrm{~mm}$, a cylinder with a volume of $160 \mathrm{ml}^{\wedge} 3$ and a heater with a capacity of $40 \mathrm{~W}$ at the hopper and $20 \mathrm{~W}$ at the tube works properly.

It is advisable to use a slightly more powerful motor for a higher retraction speed, and the hopper heater can be used weaker $(40 \mathrm{~W}$ melts the chocolate and reaches a uniform temperature of $+35^{\circ} \mathrm{C}$ in 7 minutes, and then commutes with a duty cycle of $10 \%$ ). The 20W tube heater successfully maintains $+35^{\circ} \mathrm{C}$ at a temperature of $+11^{\circ} \mathrm{C}$ in the thermal box, and then the power is not enough. It is advisable to increase the power of the tube heater to 30-35 watts. 

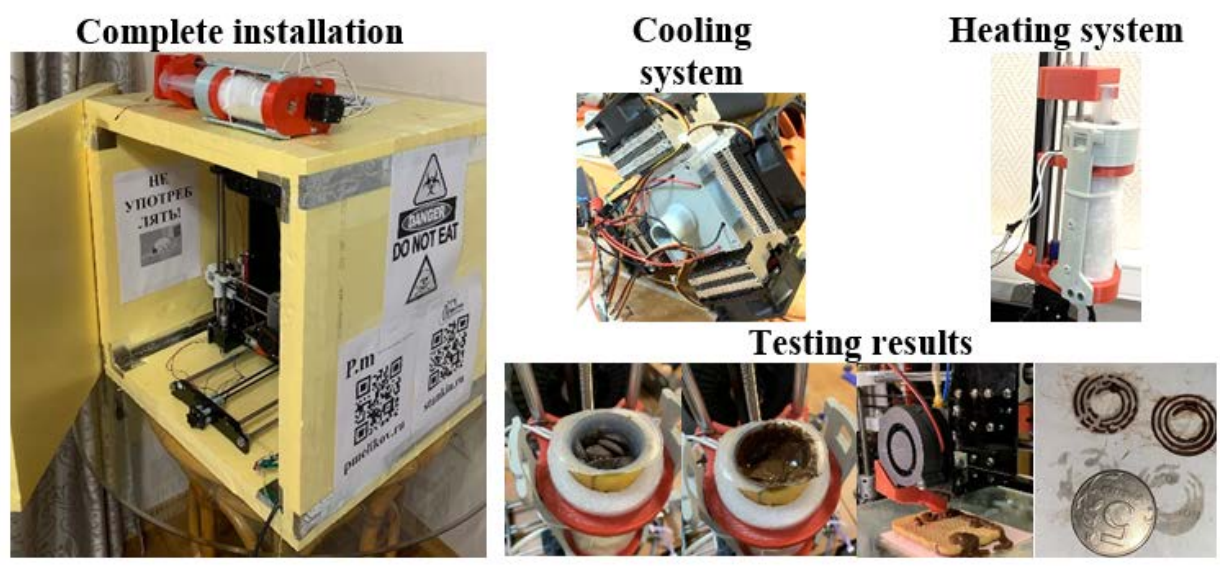

Fig. 5. A prototype of the developed solution and the result of its testing

\section{Conclusion}

The proposed system has a number of advantages over existing analogues: the ability to print food products from various materials: solid fusible materials (chocolates), liquid pastes, including baked (dough) and frozen (ice cream); the developed software environment does not require special qualifications of the operator; integration of IoT technology allows the use of remote monitoring, control and dispatching systems.

At the moment, the developed solution is partially at the stage of launching into production.

\section{References}

1. DISCOV3RY 2.0 COMPLETE // STRUCRUR3D PRINTING - [2020, https://www.structur3d.io/discov3ry-2-complete]

2. Choc Creator V2.0 Plus // TOP 3D SHOP - [2020, https://top3dshop.ru/kupit-3dprinter/choc-creator-v2-plus-ohlad.html]

3. Martinova L.I., Kozak N.V., Kovalev I.A. and Ljubimov A.B. Creation of CNC system's components for monitoring machine tool health. Int J Adv Manuf Technol (2021). https://doi.org/10.1007/s00170-021-07107-1

4. Pushkov R., Martinova L. and Evstafieva S. Extending functionality of the control system using MTConnect data collection standard. ICMTMTE 2020, IOP Conf. Series: Materials Science and Engineering 971 (2020) 042080. doi: 10.1088/1757899X/971/4/042080

5. Martinov G., Pushkov R., Martinova L., Kozak N. and Evstafieva S., 2020. Approach to development of HMI screens for CNC with dynamic kinematics. ICMTMTE 2020, MATEC Web of Conferences 329, 03026. p.1-6. doi: 10.1051/matecconf/202032903026

6. Martinova, L., Obukhov, A. and Sokolov S. Practical Aspects of Ensuring Accuracy of Machining on CNC Machine Tools within Framework of "Smart Manufacturing". 2020 International Russian Automation Conference (RusAutoCon). IEEE, 2020. Page(s): 898 - 902. 
7. Martinov, G., Kovalev, I. and Grigoriev, A., 2019. Approach to Building an Autonomous Cross-platform Automation Controller Based on the Synthesis of Separate Modules. In: International Russian Automation Conference. Sochi, Russia. doi: 10.1007/978-3-030-39225-3_15

8. Martinov, G. M., Pushkov, R. L. and Evstafieva, S. V. (2020). Collecting diagnostic operational data from $\mathrm{CNC}$ machines during operation process. In IOP Conference Series: Materials Science and Engineering (Vol. 709, No. 3, p. 033051). IOP Publishing. doi:10.1088/1757-899X/709/3/033051

9. Martinova, L., Sokolov, S. and Babin, M. (2020). Organization of Process Equipment Monitoring. In: 2019 XXI International Conference Complex Systems: Control and Modeling Problems (CSCMP). doi:10.1109/CSCMP45713.2019.8976506

10. Martinov, G., Issa, A. and Martinova, L. (2019). Controlling CAN Servo Step Drives and Their Remote Monitoring by Using Protocol OPC UA. In: 2019 International Multi-Conference on Industrial Engineering and Modern Technologies (FarEastCon). Vladivostok: IEEE, pp.1-5. doi: 10.1109/FarEastCon.2019.8934338

11. Martinov, G., Lyubimov, A. and Khoury, A. (2019). Development of Motion Controller Based on ARM Microcomputers by Supporting Different Strategies of Controlling CAN Servo Drives. In: 2019 International Multi-Conference on Industrial Engineering and Modern Technologies (FarEastCon). Vladivostok: IEEE, pp.1-6. doi: 10.1109/FarEastCon.2019.8934149

12. Martinov G. M., Nikishechkin P.A., Grigoriev A.S. and Chervonnova N. Yu. (2019). Organizing Interaction of Basic Components in the CNC System AxiOMA Control for Integrating New Technologies and Solutions // Automation and Remote Control, 2019, Vol. 80, No. 3, pp. 584-591. https://doi.org/10.1134/S0005117919030159

13. Pushkov, R., Martinova, L. and Evstafieva, S. (2018). Extending Functionality of Control System by Adding Engraving Capabilities. In: 2018 International Russian Automation Conference (RusAutoCon), Sochi, Russia. Sochi: IEEE. pp. 709-714. https://doi.org/10.1109/RUSAUTOCON.2018.8501673

14. Roman Pushkov, Evgeniy Salamatin, Svetlana Evstafieva (2018). Method of developing parametric machine cycles for modern CNC systems using high-level language. In: MATEC Web Conf. Volume 224, 2018. International Conference on Modern Trends in Manufacturing Technologies and Equipment (ICMTMTE 2018). Sevastopol, $\quad$ Russia, September 10-14, 2018. pp.1-7 https://doi.org/10.1051/matecconf/201822401116

15. Georgi M.Martinov, Anna V.Stas, Oleg A.Kudinov (2018). The approach of creating a particular postprocessor and using CNC measuring cycles. In: MATEC Web Conf. Volume 224, 2018. International Conference on Modern Trends in Manufacturing Technologies and Equipment (ICMTMTE 2018). Sevastopol, Russia, September 1014, 2018. pp.1-7 https://doi.org/10.1051/matecconf/201822404023

16. Georgi M.Martinov, Akram Al Khoury, Ahed Issa (2018). An approach of developing low cost ARM based CNC systems by controlling CAN drives. In: MATEC Web Conf. Volume 224, 2018. International Conference on Modern Trends in Manufacturing Technologies and Equipment (ICMTMTE 2018). Sevastopol, Russia, September 10-14, 2018. pp.1-6 https://doi.org/10.1051/matecconf/201822401020

17. Kovalev I, Kvashnin D., Chervonnova N. and Nikich A. Application of agile methodology at industrial manufacturing as part of the Industry 4.0. ICMTMTE 2020, IOP Conf. Series: Materials Science and Engineering 971 (2020) 052034. doi: $10.1088 / 1757-899 X / 971 / 5 / 052034$ 